\title{
TRADUÇÃO DE TEATRO GREGO: ÉDIPO REI, DE SÓFOCLES
}

\author{
Tereza Virgínia Ribeiro Barbosa \\ PROCAD - Universidade Federal de Minas Gerais \& \\ Universidade Federal de Santa Catarina \\ virginiarb@yahoo.com
}

\begin{abstract}
Resumo: Tendo em vista a especificidade do texto teatral, debatemos quais os elementos desse gênero devem ser preservados na tradução; discutimos a importância de algumas metáforas-base e das materializações no texto poético teatral como fios condutores da tradução. Finalmente, focalizamos as aparições da metáfora da terra (gê) na peça de Sófocles, Édipo Rei e suas eventuais substituições por outros termos.
\end{abstract}

Palavras-chave: gênero, tradução, metáfora, materialização.

\begin{abstract}
Considering the specificity of theatrical texts, this article debates which elements of this genre must be preserved in translation. Besides, we discuss the importance of some base-metaphors and materializations at the poetic theatrical text as lines that conduct its translation. Finally, we focus the ocurrences of the earth (ge) metaphor in Sophoclis' play Oedipus Rex and its eventual substitutions for other terms.
\end{abstract}

Keywords: genre, translation, metaphor, materialization.

A tradução dos clássicos gregos, no que tange tanto à tragédia, quanto à comédia, é questão espinhosa no Brasil. Há, por parte dos tradutores, grosso modo, dois grupos: um manifesta a necessidade de manter a aura de erudição que a literatura antiga alimentou durante séculos e prima pela escolha de um vocabulário rico, de raízes etimológicas greco-latinas; respeita a ordem das palavras e certas estruturas sintáticas, mas nem sempre corresponde a uma literalidade e precisão capazes de recuperar a magia, imediaticidade 
e oralidade do texto teatral antigo. A outra vertente atua sem preocupação com a auctoritas e a traditio e, por necessidade imposta pela cena, pelo público e pelo mercado, opta pela manipulação, com fins práticos, do texto traduzido pelos eruditos, a fim de vê-lo oralizado e corporificado para uma platéia. Desse processo vêm os textos-base mais populares na cena brasileira e se apresentam nos libretos, em geral, com a ressalva 'adaptação' - ou 'tradução' - do original francês' (efetivamente, predomina a língua de Molière, embora existam possibilidades diversas). Sem dúvida são bases muito distintas, com valores outros, distantes dos que nos propunha a cultura helênica. Estes textos - dos quais, se Platão nos ouvisse, diria serem simulacros de simulacros - criam os Édipos, Medéias e Troianas e podemos incluir também algumas Bacantes e Lisístratas (a ausência de autor é proposital, porquanto hoje a preferência seja pelo texto coletivo, o texto que passa por muitas mãos) que costumamos ver, encenações que têm grande mérito, pois mantêm vivo, senão o texto, o arquétipo, o mito, no mínimo uma imagem de uma obra literária da Antiguidade. Contudo, sabemos que aí ocorrem mutilações e adaptações drásticas as quais, mais próximas do leitor ou espectador nativo em imitações livres ou paráfrases, distanciam-nos do estranho, ardente e surpreendente mundo antigo.

Voltemos, contudo, para a academia, lugar do nosso interesse. Postularemos que as traduções acadêmicas podem e devem ser encenáveis, ou, pelo menos, acreditamos que nelas deve-se manter o objetivo de transportar, de uma língua para outra, uma espécie de texto que somente se completa na encenação: não apenas "literatura em prosa ou verso", mas teatro, com muitas informações que passam por outros sentidos. Para tanto, a tradução precisa preservar as regras básicas de um texto teatral, praticadas pela célebre tríade dos dramaturgos gregos: imediaticidade de entendimento, ritmo ligeiro (exceto quando a ocasião exige o contrário), sonoridade para facilitar a compreensão de raciocínios complexos, visualidade, brechas verbais para preenchimento com signos não-verbais facilitadores de entendimento, demonstratividade testemunhal (compreensão sem explicações; é ver e entender), espacialidade e potência para mobi- 
lidade no espaço criado, dialogicidade inclusive com captatio benevolentia. Acrescentamos que, no nosso entender, devem-se evitar, no texto teatral traduzido, explicações de mitologias, traduções dos nomes dos olímpicos (ou sua apresentação em epítetos latinos quando gregos e gregos quando latinos!), esclarecimentos de situações históricas e de trocadilhos etc. Tudo isso são clarificações ou excessos dispersivos; um espectador não lê notas e se cansa com o exagero verbal. Que não se inventem rubricas inexistentes (porque, para o leitor e também para o ator aprendiz, provocam redundância, quando não são contraditórias com o texto que já as traz implícitas) e nem um jogo de palavras mais enigmático do que o que o poeta primeiro propôs. Desenvolveremos algumas dessas normas; adiantamos, porém, que não vamos esgotá-las.

Para o ensino de língua e literaturas clássicas costuma-se dar preferência às traduções que demonstram, por parte do tradutor, conhecimento amplo da língua grega e capacidade hermenêutica, características que, acredita-se, favorecem a acuidade e literalidade. Contudo, tais traduções são, por vezes, emulativas ${ }^{1}$ demais; cegas de vaidade ${ }^{2}$, sobrecarregam o estilo direto do teatro o bastante para, em alguns trechos, concorrerem e sobrepujarem em hermetismo, sofisticação lexical e dificuldade sintática o original (e lembremos-nos de que a dificuldade sintática proposta no texto teatral é sempre resolvida, seja pela sonoridade da palavra enunciada, pelo espaço e movimento ou pela complementaridade de signos não-verbais). Estas traduções, as mais recomendadas pelos consultores dos mais diversos grupos, nas mãos dos diretores mais afamados resultam em decepções. Antunes Filho, que realizou uma bem-sucedida montagem de Medéia de Eurípides, em julho de 2001, no Sesc, São Paulo, se pronuncia a respeito:

Nós [os brasileiros] não temos uma boa educação para fala [...] Demorei muitos anos para fazer essa Medéia. Eu já tentei fazer diversas tragédias e nunca tinha conseguido sair do lugar. Depois de um mês e meio, eu parava porque os atores não sabiam falar aquilo, ficava meio pedregulho, paralelepípedo 
na boca e me machucava o ouvido. Eu fazia o rascunho e não dava certo, tinha uma plasticidade física. Fiquei muitos anos trabalhando para encontrar um método. Foi ridículo! Tive de criar o método para poder fazer o espetáculo. Sempre que vou ver uma tragédia grega, nunca entendo por que as pessoas ficam gritando. Fico contente quando as pessoas assistem e entendem, isso que é o fundamental. Eu queria que as pessoas fossem e entendessem tudo do que é uma tragédia grega. FILHO, Antunes. 2003: p.10.

O depoimento do diretor paulista, que atribui a dificuldade a uma inabilidade dos atores, parece-me colocado de forma cuidadosa, discreta e politicamente correta. Não cremos, porém, que atores que conseguem encenar textos com trechos que eu, particularmente, considero verdadeiros trava-línguas não tivessem boa capacidade de elocução. Citamos uma passagem de Gota d'água de Chico Buarque e Paulo Pontes, onde Joana prepara um veneno para Creusa e Creonte. A receita do feitiço, recitada à moda de ensalmo, é um jogo verbal que consiste em misturar conceitos, palavras e sons até o inusitado (temperódio, lagrimento, sangalho com tristezura, carnento, venemoinho) para, com o léxico, remexer as expectativas de pronúncia e escuta na enunciação de termos, servindo ao ouvinte, dessa forma, um repasto vocabular em uma "estranha mesa". O resultado é um conjunto de frases de difícil execução, mas que foram sempre ditas com maestria pelos atores ${ }^{3}$ :

“Tudo está na natureza,

Encadeado e em movimento -

Cuspe, veneno, tristeza, Carne, moinho, lamento,

Ódio, dor, cebola e coentro,

Gordura, sangue, frieza,

Isso tudo está no centro

De uma mesma e estranha mesa

Misture cada elemento - 
Uma pitada de dor,

Uma colher de fomento,

Uma gota de terror

O suco dos sentimentos,

Raiva, medo ou desamor,

Produz novos condimentos,

Lágrima, pus e suor

Mas, inverta o segmento,

Intensifique a mistura,

Temperódio, lagrimento,

Sangalho com tristezura,

Carnento, venemoinho,

Remexa tudo por dentro,

Passe tudo no moinho,

Moa a carne, sangue e coentro,

Chore e envenene a gordura,

Você terá um ungüento,

Uma baba, grossa e escura,

Essência do eu tormento

E molho de uma fritura

De paladar violento

Que engolindo, a criatura

Repara o meu sofrimento

Co'a morte, lenta e segura.

(BUARQUE, 1975: p. 206)

Acreditando que não devemos penalizar os atores, admitimos que algumas traduções se apresentam de forma tão complicada (quase ininteligíveis) que também para os neo-acadêmicos, seu público-alvo, soam embaraçosas e enfadonhas. São utilíssimas como objeto de verificação, de despertar de imagens possíveis; ou consultadas, vez por outra, quando o texto grego suscita dúvidas mais ásperas; todavia, infelizmente, no que diz respeito à encenação, acarretam tantas dificuldades que raramente vemos encenação destes textos. Podemos afirmar, pela prática, que os grupos teatrais não se sentem motivados pela tríade grega tal como ela se apresenta no mercado em língua portuguesa. 
$\mathrm{O}$ teatro grego antigo - fato que a grande maioria de diretores e atores desconhece - se funda a partir de uma intrincada rede, costurada não somente na composição histórica do texto (local, data e função) como também por outra tessitura histórica - a produção do manuscrito, se em pergaminho ou papiro, se um palimpsesto; depois dessas etapas, segue-se outra ainda impossível no Brasil como prática regular, o estabelecimento do texto, com as várias etapas de uma edição com aparato crítico, para só então começar a aventura da tradução, direta do grego, ou, como sói frequentemente acontecer, do alemão, francês, italiano ou inglês. Como se pode observar, antes da interpretação e da tradução, existem muitos et ceteras.

De ordinário um tradutor de teatro grego enfrenta problemas. As melhores edições críticas são caras e estrangeiras e, como antecipamos, raramente se tem acesso aos manuscritos os quais exigem técnica para sua leitura. Acresce que o texto de teatro - nosso foco - é, por natureza, 'lacunar'; em suas lacunas, existe uma avidez natural por outros signos não-verbais os quais - se quisermos guardar minimamente a estrangeiridade do texto - devem ser preenchidos pela cultura e, em nosso caso, arrancados do passado através de pesquisa nas áreas de história e costumes, geografia, política, mitologia, etc., função que cabe ao diretor e/ou encenador suprir como desejar.

Donde se conclui: os textos de teatro grego não são próximos nem no espaço nem no tempo. Não importa a qualidade da tradução, não há como recuperar o ritmo de longas e breves, de metros diferenciados, de dialetos harmonizados, tudo o que é específico da língua grega dos finais do séc. VI e de todo o século V. Some-se a isso que o gênero escolhido, por sua simultaneidade com o movimento da sofística, destaca-se por intenções múltiplas, relativas ou apenas sugeridas de modo a exigir de seu receptor um trabalho incansável de movimentos invertidos, posições contrárias tomadas de frente e de avesso, relações complexas que se fazem entender e deslindar aos poucos, mas que depois de desembaraçadas reclamam a antiga complexidade e anseiam pela solução da cena teatral. 
Ambigüidades, enigmas, paradoxos, silogismos, influências da oratória de Protágoras, Górgias e outros, são atores textuais relevantes. Ademais fazem parte do espírito trágico e cômico de qualquer peça grega do chamado período clássico as encruzilhadas de sentido e os mistérios que levam o protagonista a uma derrocada (banal e com sucesso posterior, no caso da comédia). Nesse aspecto, típico é o Édipo Rei, de Sófocles: labiríntico, paradoxal, cruzado e ambívio; entretanto, plenamente alcançável e até íntimo no que se refere a nossa humanidade. Repetindo, os textos de teatro antigo são distanciados no tempo e no espaço, mas não difíceis; todavia o entendimento passa por outros lugares que não somente $o$ texto - é preciso visualizar a cena, enxergar movimentos, escutar os sons. Sófocles utiliza-se recursos análogos aos de Chico Buarque, que, em suas misturas lexicais, construiu o veneno pela palavra no trecho citado de Gota d'água. O poeta grego, porém, fá-lo em 1530 versos e com obstinação, verso a verso, cena a cena, a ponto de, em metalinguagem, colocar na boca de Jocasta a pergunta: "Mas que é isto? Que força dupla têm estas coisas [palavras]?!” (v.938). Múltiplas e abertas são as interpretações, seja linearmente falando, seja na construção dos personagens e, para complicar um pouco mais, na língua grega antiga; mas sua dificuldade é a mesma de toda e qualquer literatura de qualidade.

Também como papel dramático, as encruzilhadas permeiam toda a trajetória de Édipo, e, como que sob o efeito de uma maldição, o texto escrito para o filho de Laio, ao se tornar objeto de tradução, se metamorfoseia e às vezes se monstrifica em veredas entretecidas com sentidos paralelos; multiplica-se diante dos olhos que o lêem, em possibilidades de interpretação, encenação e preenchimento de lacunas por signos variados.

Sua leitura hoje mais básica é ideologicamente marcada pela escola freudiana: Édipo é o indivíduo que deseja a mãe. Não negamos o que Sófocles escreveu: uma só cama uniu mãe e filho. Porém, não devemos esquecer que o tragediógrafo não conheceu a psicanálise e que o leito de Édipo e Jocasta, muito mais largo do que podemos 
imaginar, não se assemelha a um divã. Para expressá-lo, utiliza-se a poética do entrelaçamento do princípio ao fim da peça. Consideraremos apenas uma metáfora (entre outras também poderosíssimas e sobremaneira comentadas): a da terra, desdobrada em semeador, semente, árvore, fruto e ceifa, praga e peste, metáforas, aliás, muito adequadas para uma obra constituída como parte do ritual de Dioniso e imagem poderosa particularmente para falar da cidade de Tebas, cujos primeiros habitantes nasceram da semeadura dos dentes do dragão na terra. Tebas: mãe de homens e deuses. Nesse universo, numa cultura ainda agrária, embora sofisticadamente intelectualizada na pólis, nasce o Édipo Rei de Sófocles.

Ele nasce de uma mãe muito especial. Essa categoria, expressa no termo meter - mãe (ou em sua forma dialetal, máter) tão preciosa à leitura freudiana, aparece na obra 21 vezes $^{4}$. Não é pouco; mas a palavra gê (ou em sua forma dialetal gâ), terra, se faz presente 35 vezes. As duas, só para vislumbrar a metáfora, são suficientemente marcadas para percorrerem toda a peça. Variá-las na tradução é manipular o texto. Substituir a palavra terra por chão, por exemplo, é masculinizá-la e o masculino não pode ser mãe.

Vale citar Gaston Bachelard, que, na Poética do Devaneio (2001: p.31) exclama:

[...] de uma língua para outra, que magnífica hora de leitura quando se conquista um feminino! Um feminino conquistado pode aprofundar todo um poema. Assim, numa poesia de Heinrich Heine, o poeta conta o sonho de um abeto isolado que dormita sob o gelo e a neve, perdido no ermo de uma charneca do Norte: "O abeto sonha com uma palmeira que além, muito além, no longínquo Oriente, se desola solitária e taciturna na encosta de um rochedo adusto." Abeto do Norte, palmeira do Sul, solidão glacial, solidão adusta, é sobre essas antíteses que um leitor francês deve sonhar. Quantos devaneios não são oferecidos ao leitor alemão, já que em sua língua a palavra abeto é masculina e a palavra palmeira é feminina! Na árvore ereta e vigorosa sob o gelo, quantos sonhos dirigidos para a árvore feminina, aberta com todas as suas palmas, atenta a todas as brisas! 
A palavra terra, no Édipo Rei, em sua forma lexical gêlgâ, esquecidos correlatos como região e outros que levam para um campo semântico mais abstrato e menos mitológico, é nosso foco. Chthón, chthonós, por exemplo, palavra feminina, é terra enquanto extensão, solo, país, região. Ocorre 10 vezes na peça, uma delas, de forma curiosa, no verso 301, quando Édipo diz: "Ó Tirésias que entendes tudo, coisas aprendidas e indizíveis, celestes e também repisadas em savanas (chthnostibê) ..." Aqui o contexto é pragmático, não alude à fusão de concreto e mítico que o termo gê/gâ carrega, inclusive no português (recordemos a letra de Milton Nascimento, em Cio da Terra: "Afagar a terra/ Conhecer os desejos da terra/ Cio da terra, a propícia estação/ E fecundar o chão.”).

Outro correlato de terra $(g \hat{e} / g \hat{a})$, a palavra pédon, neutra, significando chão; com 2 aparições somente, é mais displicente, corriqueira, e, nos contextos selecionados, vulgar, quase blasfema - "e no chão, em indignidade homicida, jaz uma geração sem pranto..." (v.181); "Que se dane o que eu era e o pastor que me tirou do rude chão que suporta os pés e que da morte me livrou!” (v. 1349)

Não percorreremos todas as terras, mas garantimos que a palavra é valiosa demais para pretendermos substituí-la ou eliminá-la da tradução; imaginemos, entretanto, a troca por Tebas ou pólis, cidade: fazemo-la politizada, urbanizada, pavimentada; ela perde em largueza e força primitiva. É ainda desmetaforizá-la. Mas pólis, cidade, figura no texto 24 vezes; é bastante também. Se computarmos, temos, estatisticamente, as importâncias assim definidas: terra, pólis e mãe, sendo que as duas últimas estão próximas, numericamente, ao passo que o termo ge leva grande vantagem.

Focalizando, portanto, a terra e a metáfora que ela veicula: Édipo é quem governa a terra (v.54), é quem pretende desagravála (v.136); quem expulsará dela o criminoso (v.229), pois que ela, como Jocasta, é mãe, feminino que gera e que na situação do drama sofre (v.254). Lembremos-nos de que a Jocasta foi vedado ter, com Laio, filhos. Aquele que dela nascesse deveria ser morto, o caso de Édipo. Por duas vezes, nos versos 1256-57 e 1403-8, o 
poeta une claramente as palavras mulher, mãe, semente e campo plantado. Traduzimos:

"e [ele] pedindo para indicar a mulher e... não mulher... a matriz... Onde acharia a dupla seara, dele e de frutos." (v.1256-57); "ó núpcias, núpcias, concebestes-nos e os que foram concebidos, de novo, com uma mesma semente, plantastes; e produziste pais, irmãos, filhos, sangue entroncado, noivas, mulheres e também mães e tudo que é obra de mais vergonhosa entre humanos." (v. 1403-8).

As piores pragas que podem recair sobre alguém, de acordo com o texto, são que sua terra não gere fruto e que a mulher não tenha filhos (v. 270-1); a pior pena é o exílio (v.309). A terra é manto dos que morrem (v.416); ela acolhe e também rejeita (v.1427-8); ela sofre (v.635).

Homem e terra estão ligados. A imagem da labuta do homem para o plantio da lavoura, por exemplo, aparece de forma sugestiva; o corifeu exorta o rei da seguinte maneira: "Ó senhor, digo não somente uma vez, mas sabe que insensato e bloqueado na idéia eu me mostraria se te descartasse, tu que a minha querida terra, em labutas, remexida nos conformes, fofas (úrisas, arejar)." (v. 689-696) Tradução provocante. A partir do trabalho com a terra, da necessidade de arear a raiz para a planta produzir frutos; utilizamos os verbos remexer e fofar, ambos com sentido secundário sexual.

Igualmente ambígua será a resposta do oráculo de Delfos para Édipo; em palavras dele próprio, lemos, no verso 791: "que precisava ser misturado (michthênai) com a mãe" e em 995, "que era preciso misturar-me (migênai) com minha própria mãe”. O verbo mígnymi ou meígnymi se encarrega de amplificar e complicar a frase, pois, estritamente, segundo Liddell-Scott, significa: misturar líquidos (Ésquilo, Coéforas, 546), confundir substâncias (fluidos e sólidos); seguem-se os sentidos secundários de ajuntar, reu- 
nir, bater-se, combater no corpo a corpo (Sófocles, Édipo em Colono, 1047). O contexto erótico está camuflado, pois a linguagem oracular é enigmática e nela registrou-se um obscuro migênai em lugar de um zygênai/zeúgnymi $i^{5}$ (v.826) ou de um nympheúo ${ }^{6}$ (v.980) ou, ainda, de um ksyneunástesan ${ }^{7}$ (v.982); ou de um gaméo/gamos $^{8}$ (v. 825 , v.1199, v.1214 - 2 vezes, v. $1403-2$ vezes, v.1492, v.1500, v.1502). Importante: a forma migênai traz em si a palavra gê. Confundir-se, misturar-se com a mãe é muito mais abrangente, pois serve para uma mistura simples, um ato sexual, um combate de corpos $^{9}$, uma mistura política. Sófocles permite interpretações demais para que a limitemos a um único viés. O verbo comentado pode evocar emoções ${ }^{10}$ (que também são um estado de coisas na peça) simultaneamente favoráveis e hostis. Realçamos que, em Sófocles, é necessário guardar a maior exatidão na tradução palavra a palavra, porque, como vimos, o poeta não as escolheu por acaso. Situado o problema, focalizaremos, conforme explicitamos antes como qualidade do texto teatral, a visualidade.

A técnica é interessante e para perceber o alcance desse recurso na Grécia, mas, sobretudo, na atualidade, buscamos uma teorização de Viktor Chklovski (1917) no brevíssimo A Arte como Procedimento. Chklovski propõe reflexões que, aparada a enorme distância que o separa da poética grega, podem-nos ajudar a compreender o destaque dado ao que se pode ver, não necessariamente com o aparelho ótico (enxergar, como a pintura para Da Vinci, também é cosa mentale):

O objetivo da arte é dar a sensação do objeto como visão [...]; o procedimento da arte é o procedimento da singularização dos objetos e o procedimento que consiste em obscurecer a forma, aumentar a dificuldade e a duração da percepção. $\mathrm{O}$ ato de percepção em arte é um fim em si mesmo e deve ser prolongado; a arte é um meio de experimentar o devir do objeto, o que é já "passado" não importa para a arte. (1978, p. 45) O objetivo da imagem não é tornar mais próxima de nossa compreensão a significação que ela traz, mas criar uma 
percepção particular do objeto, criar uma visão e não o seu reconhecimento. (1978, p. 50)

Assim, com sua técnica, o Sófocles dramaturgo será capaz de materializar conceitos, ações e palavras em objetos mentais. André Lefevere (1997: p.66) comenta a introdução de Gilbert Seldes à Lisístrata na qual o tradutor propõe, inclusive, a criação de novas cenas, além de cortes com a intenção de 'atualizar' Aristófanes (exatamente como no Brasil). Com esses propósitos, assistimos a peças nas quais se omitem na encenação os tais trechos, ditos como 'pesados e cansativos'. A alegação é sempre a mesma: busca-se mais agilidade e teatralidade, evita-se o tédio da platéia, pretendese recuperar as origens mais primevas da arte teatral, isto é, a ação, preconizada por Aristóteles.

Admitimos que isso seja obrigatório nas montagens, porque algo de monstruoso antecedeu a leitura do texto pelos atores e diretores; de fato, o texto grego é sempre vivo, dramaticamente bem escrito e extraordinariamente encenável. Isso não é de surpreender, posto que, quando Téspis introduziu um ator a dialogar com o coro, já antes de Ésquilo, Sófocles e Eurípides, ele estabeleceu as regras dramáticas de um jogo dinâmico que se realiza a partir de um diálogo mascarado. Nesse momento da invenção, a preocupação com a dramaturgia tornou-se regra.

Dando continuidade à nossa observação de trechos agora visuais, apresentamos mais alguns versos do Édipo Rei de Sófocles, apontamos para uma rápida comparação com trechos da Poética de Aristóteles e sugerimos interpretações para a passagem de 475-481.

Os dois primeiros trechos são versos de mensageiro e podemos por isso pensar, guardadas as devidas proporções, que o discurso dessa personagem trágica se aproxima do sensacionalismo da chamada imprensa marrom, que chega e mostra para o público, com palavras espetaculares, aquilo que esteve oculto na skené, especificamente na alcova incestuosa dos labdácidas. Abre-se no discur- 
so uma janela para um novo palco, proibido para os olhos e, porque interdito, desejado e imaginado ${ }^{11}$.

Os recursos para excitar a mente são os seguintes: ele fala no tempo presente de um passado que presenciou e, numa espécie de 'perfectivo', traz o passado para o presente, onde o veremos com seus resultados terríveis. Dessa forma, o mensageiro não entra em cena para 'esticar' a peça, mas para engatilhar um tiro (STÉFANIS, 1997: 137), um torpedo, e com isso gerar curiosidade, fascínio, tensão e medo. Sua fala deve ter força suficiente para fazer ver o espaço da ação, o tempo detalhado em que cada golpe aconteceu, as dificuldades de execução, o efeito sobre os circunstantes, as palavras de cada um, tal como foram ditas. De sua fala uma cena se erige: a cena do crime.

Inseridos no discurso bombástico e apelativo do mensageiro, os versos que escolhemos servirão para contar o que se passou com Édipo, longe de nosso olhar no instante mais dramático de sua existência. A audiência sente que perdeu algo importante. Lamentavelmente não presenciamos esse momento. Mas como não? Vamos presenciá-lo pela reportagem de um exímio jogador de palavras.

O primeiro recorte é a descrição do homem desconhecido, do assassino de Laio, ou melhor, sua materialização através da imagem de um touro errante (e recordamos, oportunamente, que o animal é símbolo de Dioniso) perdido em idas e vindas. Os versos do coro: "vai e volta, pois, por floresta agreste, em cima e abaixo do antro, e entre pedras, o touro infeliz, com infeliz pé, carente, fugido das coisas do umbigo da terra, as adivinhas..." Destacamos o verbo phoitáo (parece-nos que o termo é substitutivo de hamartáno, no sentido de passar por caminhos equivocados): "vai e volta pedindo-nos mostrar [...]" (v. 1255). Um cognato de phoitáo peripoléo, "vagar em círculos" - que ocorre em 1254, é, da mesma forma, útil para visualizarmos um conceito aristotélico importante, a hamartía: "olhávamos aquele que, em círculo, vagava." Esses termos funcionam como materializadores visuais do erro (hamartía). O conceito é mostrado em Édipo Rei em passagens que 
levam o ouvinte a ver gestos extremamente significativos no contexto dionisíaco.

Édipo, homem-touro acuado, será o protagonista nos versos do mensageiro. A personagem sem nome entra com alarde e, exclamando, nomeia seu ouvinte (v. 1223): "ó sempre muito honrados desta terra" e conclui ainda com tom enfático (v.1224-5): "que obras escutareis! Que coisas enxergareis! Quanta dor suportareis..." Em seus exageros afirma que nem dois rios volumosos (o Danúbio e o Fásin) poderiam lavar os crimes da casa dos labdácidas. A imagem é concreta, a água desses rios é conhecida, sabe-se da sua pujança, força e cor. Depois o mensageiro continua: "quanta coisa [a casa] esconde, males que logo a luz mostrará!”.

O coro que, de imediato, simboliza os sempre muito honrados, reage curioso e assustado (v.1232): "nem as coisas que antes sabíamos... acaso falta algo para haver uma dor profunda...". Sua ansiedade é rapidamente apagada com a notícia de que Jocasta morreu. E tudo poderia ficar apaziguado na mais curta e rápida das frases, não fosse a curiosidade crescente dos velhos tebanos, que abre caminho para o longo e detalhado discurso do núncio, agora com toda a atenção voltada para si.

Sua mensagem estará carregada de superlativos, de incitamentos para ver o que não se pode ver (cf. por exemplo, v. 1238), de realidades subjetivas como a incerteza angustiante de Jocasta (cf. o v. 1247). A variedade de verbos para exprimir os sons, impressionan$t^{12}$, é empregada com o intuito de preparar olhos e ouvidos para uma experiência cada vez mais dolorosa a fim de, pela sugestão do ver e escutar o que não se deve, presentificar. O fato de Édipo estar longe dos olhos gera mais agonia: não há meios de ajudá-lo.

Numerosas riquezas e complexidades, a título de exemplo, poderíamos realçar: o ato de bacante realizado por Jocasta e expresso apenas pelo particípio presente spôsa (v.1243) - que remete a um termo-chave para o teatro de Dioniso, sparagmós, dilaceramento - e o ato de bacante de Édipo, manifesto em apospásas.

Concentramo-nos na passagem onde o enviado, para contar, expressa um desejo do rei. Trata-se de uma estrutura em discurso 
indireto livre, uma oração declarativa onde Édipo afirma: "que não o queiram ver!". O verso é sofisticado, se é que algum verso do Édipo Rei possa não sê-lo. Porém a sofisticação advém de sua dupla força, real e técnica: 'não se deve querer ver o rei que está fora do campo de visão' e 'não se deve ver o rei em estado lastimável', isto é, a visão de Édipo provocará o horror trágico. Na mesma direção, o verso 1272: “...nem como sofria, nem que males fazia.” Traduzimos, dessa forma, a seqüência: "Ele gritava assim: que não o queiram ver! Nem como sofria, nem que males fazia!”.

Se observarmos cuidadosamente, perceberemos os elementos constituintes de uma ação trágica, do modo como o filósofo estagirita a definiu na Poética 1449b, 24, presentes nesses versos: um objeto, o rei, ele mesmo apresentado como um espetáculo - ópsis - doloroso; a experimentação do páthos que acomete o protagonista e por fim a ação.

Os versos 1273 e 1274 são vertidos em geral com uma perspectiva simplista tomada exclusivamente para a situação dramática de Édipo fora de cena. Contudo a sintaxe de Sófocles é direta, descomplicada (o que não impede os múltiplos sentidos) e, no nosso ponto de vista, contempla tanto a circunstância em que o filho de Laio se encontra, quanto a situação técnica de que fala o arauto no contexto da encenação: há coisas que devem ficar no escuro da skené, fora do alcance da vista. À situação da personagem que no futuro não mais enxergará devido à autopunição e ao ato dionisíaco que infligiu a si próprio soma-se a necessidade cênica: Édipo não pode ser visto no ato da mutilação, que pudemos 'ver' somente pelas palavras do mensageiro. Por este motivo, sugerimos, para estes versos, a tradução: "mas no escuro fica o resto, para os que não era preciso ver... para os que carecia não conhecer." A palavra loipón, frequentemente traduzida por 'futuro' e restritamente entendida como uma limitação somente para Édipo, pode, sem prejuízo da primeira leitura, ser ampliada para a platéia. O resto ficará, para sempre, in off, no escuro, para os que não deviam assistir às cenas de suicídio de Jocasta e de cegamento de Édipo. Tecnicamente, o mensageiro instiga a imaginação e frustra o desejo de seu público, que mais que nunca almeja ver Édipo mutilado, objeto de 
horror, como um espetáculo. O poeta acrescenta na passagem o limite para ver e saber, questão inerente a qualquer texto que se pretende tragédia.

\section{Notas}

1. Cf. Vitor Hugo.

2. Sirvo-me aqui dos ensinamentos de Juan Luis Vives, em Versões ou Traduções, p.127 (em tradução de Mauri Furlan). In. Mauri Furlan (org.), Clássicos da Teoria da Tradução.

3. Em outros casos - como fomento e fermento - pode-se simplesmente trocar o uso esperado no contexto de enunciação. Recomendo a gravação de Bibi Ferreira (1977), de expressividade e dicção ímpares.

4. Valho-me outra vez das instruções de Vives, em Versões ou Traduções, p.125. In. Mauri Furlan (org.), Clássicos da Teoria da Tradução.

5. Enlaçar.

6. Desposar.

7. Ajuntar-se na mesma cama.

8. Casar, tomar uma mulher para si.

9. Borges, na conferência A metáfora, nos ajuda a entrar nesse campo de entendimento metafórico: "Temos ainda as metáforas para batalha. Algumas delas são bem banais - por exemplo, 'encontro de homens'. Aqui talvez, haja algo bastante sutil: a idéia de homens se reunindo para matar uns aos outros (como se não houvesse outros 'encontros' possíveis)". 
10. Paixão amorosa, ódio guerreiro, afeto, atração física, reação química.

11. Sobre o desejo proibido: cf. Platão. República, IV, 439 e 440 a. Destaco a passagem 440a: "Leôncio, filho de Agláion, ao regressar do Pireu, pelo lado de fora da muralha norte, percebendo que havia cadáveres que jaziam junto do carrasco, teve um grande desejo de os ver, ao mesmo tempo que isso lhe era insuportável e se desviava; durante algum tempo lutou consigo mesmo e velou o rosto; por fim, vencido pelo desejo, abriu muito os olhos e correu em direção aos cadáveres, exclamando: “Aqui tendes, gênios do mal, saciai-vos deste belo espetáculo!"." (tradução Maria Helena da Rocha Pereira).

12. Epirráksa, kalề, goâto, boôn, eksaitôn, deinon d'aúsas, brychntheís, audôn (2 vezes), ephymnôn, stenagmós, boâi.

\section{Bibliografia}

ARISTÓteleS. Poética. Trad. de Eudoro de Sousa. Lisboa: Casa da moeda, 1992.

. Poetics. Introd., comm. and appendices by D. W. Lucas. Oxford: Clarendon $\overline{\text { Press, }} 1968$.

BACHElAR, G. Poética do Devaneio. Trad. de Antônio de Pádua Danesi. São Paulo: Martins Fontes, 2001.

BERMAN, A. La traduction et la lettre ou l'auberge du lointain. Paris: Éditions du Seuil, 1999.

FILHO, Antunes. Antunes Filho, entrevista. In: GARCIA, E. B. e ALMEIDA, M. de, (ed) Entrevistas: processos. São Paulo: Sesc São Paulo, 2003. 
GUERINI, A. Gênero e tradução no Zibaldone de Leopardi. São Paulo: EDUSP; Florianópolis: UFSC/PGET, 2007.

HOPKINS, D., STUART, G. (ed.) The Oxford History of Literary Translation in English. Vol 3. Oxford: Oxford University Press, 2005.

NASCIMENTO, M. Cio da terra. Consultado em 30/07/2008. In: http:// ociodaterra.miltonnascimento.letrasdemusicas.com.br

LEFEVERE, A. Traducción reescritura y la manipulación del canon literario. Tradução de $\mathrm{M}^{\mathrm{a}}$ Carmen África e Román Alvarez. Salamanca: Colegio de Espana, 1997.

LIDELL, H. G. \& SCOTT, R. A Greek-English Lexicon. Oxford: Clarendon Press, 1968.

PLATÃO, Repubblica. Milão: Grandi Tascalili Economici, 1997.

. República. Trad. de $\mathrm{M}^{\mathrm{a}}$ Helena da Rocha Pereira. Lisboa: Calouste Gulbenkian, 1983.

RYNGAERT, J-P. Introduction à l'analyse du théâtre. Paris: Bordas, 1991. SÓFOCLES. Oedipus Rex. R. S. Dawe (ed.) Cambridge: Cambridge University Press, 2006.

STÉFANIS, A. Le messager dans la tragédie grecque. Academia de Atenas: Atenas, 1997.

VENUTI, L. Escândalos da Tradução. Trad. de Laureano Pelegrin; Lucinéia M. Villela; Marileide D. Esquerda e Valéria Biondo. Bauru: EDUSC, 2002.

VIVES, J. L. Versões ou Traduções. Trad.de Mauri Furlan. In. Mauri Furlan (org.), Clássicos da Teoria da Tradução. Florianópolis: Núcleo de Pesquisas em Literatura e Tradução/ UFSC, 2006. 